\title{
(Re)pensando a gerência em enfermagem a partir de conceitos utilizados no campo da Saúde Coletiva
}

\author{
(Re)thinking nursing management based \\ on Collective Health concepts
}

Carla Aparecida Spagnol 1

\footnotetext{
1 Escola de Enfermagem da Universidade Federal de Minas Gerais. Av. Alfredo Balena 190, Santa Efigênia, 30130-100, Belo Horizonte MG. spagnol@ufmg.br
}

Abstract Studies show that in order to manage nursing care, nurses use management methods and strategies based on the classic administration theory. This management style does not enable nursing workers to create collective spaces, where they can act as social subjects. Based on the principle that nursing management needs, at the moment, to be seen and exercised under a new view, the author aims at elaborating a reflection on this practice, using the concepts of collective and social subject that are fundamental to Collective Health. Thus, the possibility of approaching this field contributed to expand the author's knowledge and concerns regarding the theme as well as to better understand the nursing theme as a collective of social subjects in action. Therefore, it is important to emphasize that the workers are human beings with their own interests, needs and wishes, producing social relations as they constantly interact with other subjects and are able to build capacities to intervene in this reality. This organized group has the main objective to provide an integral care to the population, performing actions in an ethic, secure and humanized direction.

Key words Nursing management, Nursing, Collective health
Resumo Estudos mostram que para gerenciar a assistência de enfermagem, o enfermeiro utiliza métodos e estratégias de gestão oriundos da teoria clássica da administração. Este estilo de gerência não tem permitido aos trabalhadores de enfermagem criarem espaços coletivos de gestão, onde possam atuar como sujeitos sociais. Partindo do princípio de que a gerência em enfermagem necessita, na atualidade, ser vista e exercitada sob um novo olhar, procurou-se neste ensaio teórico elaborar uma reflexão acerca desta prática, utilizando os conceitos de sujeito social e de coletivo, que são fundamentais no campo da Saúde Coletiva. Assim, aproximar deste campo, além de contribuir para ampliar os conhecimentos e os questionamentos acerca da temática, contribuiu também para compreender a equipe de enfermagem como um coletivo de sujeitos sociais em ação, visto que os trabalhadores são seres humanos dotados de interesses próprios, de necessidades e de desejos, que produzem relações sociais, na medida em que interagem constantemente com outros sujeitos e podem adquirir capacidade para intervir na sua realidade. Este coletivo organizado possui como objetivo principal a prestação de uma assistência integral à população, realizando ações de forma ética, digna, segura e humanizada.

Palavras-chave Gerência em enfermagem, Enfermagem, Saúde coletiva 


\section{Introdução}

O enfermeiro tem basicamente quatro atividades essenciais que norteiam a sua profissão: assistencial, gerencial, educativa e de pesquisa. No cotidiano de trabalho, estas atividades não podem ser desenvolvidas separadamente, pois a intersecção entre elas é um fator importante para prestar assistência de enfermagem de forma segura e livre de riscos à população. Mesmo reconhecendo a importância desta articulação, optou-se por destacar a função gerencial do enfermeiro, propondo neste ensaio teórico uma reflexão acerca do seu exercício na prática profissional.

O recorte se justifica, pois, desde a época em que atuava como enfermeira em unidades de internação na área hospitalar, até hoje, momento em que atuo como docente na Escola de Enfermagem da Universidade Federal de Minas Gerais (EEUFMG). Ao ministrar as disciplinas da área de Administração em Enfermagem, venho levantando e indagando questões acerca do processo de gestão em saúde e principalmente na enfermagem.

Nos diversos serviços de saúde, especificamente no âmbito hospitalar, a gerência em enfermagem tem assumido fundamental importância na articulação entre os vários profissionais da equipe, além de organizar o processo de trabalho da enfermagem, buscando concretizar as ações a serem realizadas junto com clientes, que buscam estes serviços para atender às suas necessidades de saúde-doença.

$\mathrm{Na}$ enfermagem, o profissional responsável legalmente para assumir a atividade gerencial é o enfermeiro, a quem compete a coordenação da equipe de técnicos e auxiliares de enfermagem, condução e viabilização do processo cuidativo, tendo como princípio norteador de suas ações o direito da população à saúde integral, realizadas de forma digna, segura e ética.

Para entender como ocorreu a gênese da administração na enfermagem, recorreu-se a literatura e procurou-se descrever de forma sintética como se constituiu histórica e socialmente este conhecimento na profissão.

Desde o início da Era Cristã e durante toda a Idade Média, o trabalho da enfermagem era pautado no modelo religioso, que se restringia à caridade e ao conforto da alma dos doentes. Mas, a partir do século 19 na Inglaterra, a enfermeira Florence Nightingale com sua vocação para cuidar dos doentes, sua determinação para institucionalizar a profissão de enferma- gem e a experiência que adquiriu durante os estágios que desenvolveu com as diaconisas de Kaiserwerth na Alemanha, configurou um outro processo de trabalho para a enfermagem, a partir das suas propostas de reorganização dos hospitais militares, implementadas durante a guerra da Criméia. Além disso, esta enfermeira institucionalizou o ensino de enfermagem, criando a primeira escola em 1860, que formava as ladies nurses para se responsabilizarem pela administração dos hospitais e as nurses para prestarem assistência aos pacientes.

Segundo Almeida (apud Gomes, 1991), as técnicas e os procedimentos de enfermagem que começaram a ser organizados no final do século 19 na Inglaterra foram um dos pontos fundamentais para uma sistematização inicial do saber da profissão, sendo considerados um dos primeiros instrumentos que a enfermagem utilizou para manipular o corpo doente. Aliado a este saber, Gomes (1991) cita que o conhecimento de administração na enfermagem também se constituiu como instrumento de trabalho que contribuiu para organizar o ambiente terapêutico onde o cuidado era realizado.

De acordo com Carvalho (apud Gomes, 1991), apesar de o saber administrativo na enfermagem ter se constituído no trabalho prático, por ocasião do surgimento da enfermagem moderna, este só se formalizou na Inglaterra por volta de 1900, quando a duração do curso foi modificada. A partir desse momento, o curso deveria oferecer às alunas especiais (ladies nurses) um ano de instrução, incluindo-se no currículo aulas sobre administração e chefia, bem como a realização de mais dois anos de prática. Quanto às demais alunas (nurses) o curso não oferecia preparo em administração, estando programado para ser oferecido um ano de instrução e mais três anos de prática supervisionada.

Assim, Florence Nightingale foi considerada a enfermeira pioneira a introduzir a administração no ambiente hospitalar, consolidando de forma precoce o princípio da divisão do trabalho na enfermagem, ou seja, as ladies nurses deveriam pensar e administrar o trabalho e as nurses deveriam executá-lo. Em seu livro Notas sobre a enfermagem, a autora deixa clara a função gerencial do enfermeiro e mostra a importância do conhecimento de administração para a profissão, conforme evidencia o trecho: todos os benefícios de uma boa enfermagem apresentados nestas notas podem ser completamente anulados por deficiência, por exemplo, na administração básica, ou melhor, por se ignorar como 
proceder para que o que é feito quando se está presente o seja também quando se está ausente (Nightingale, 1989).

Sendo assim, a gênese do conhecimento da administração em enfermagem se constituiu histórica e socialmente a partir do modo como Florence praticava e ensinava enfermagem, utilizando já naquela época métodos de racionalização do trabalho.

A enfermagem nightingaleana se expandiu pelo mundo ocidental, influenciando de forma decisiva a estruturação da nova profissão ( $\mathrm{Pi}$ res, 1989). Este modelo chega aos Estados Unidos por volta de 1873 e teve seu foco voltado principalmente para a execução de tarefas e procedimentos realizados em um menor tempo possível (Backes, 1999).

No Brasil, o ensino e a prática da enfermagem, também foram influenciados pelo modelo nightingale. Este fato se concretizou quando em 1921 o dr. Carlos Chagas, que respondia pelo Departamento Nacional de Saúde Pública (DNSP), após visitar os serviços de saúde americano, que estava estruturado nos moldes nightingaleanos, se empenhou em criar o Serviço de Enfermeiros de Saúde Pública e uma escola de enfermagem nos padrões do modelo que conheceu. Assim, órgãos internacionais como a Fundação Rockefeller contribuíram para o financiamento deste projeto, além de enviarem enfermeiras norte-americanas para avaliar e implementar as ações propostas para a enfermagem brasileira (Backes, 1999).

Foi criada então no Brasil, em 1923 a Escola de Enfermeiras D. Ana Neri que representa o marco fundamental na história da estruturação da enfermagem como profissão (Pires, 1989). Em relação ao primeiro programa de ensino oficial desta Escola, Rizzotto (1995) refere que este não se diferenciava do Standart Curriculum for Schools of Nursing que estava em vigor nos Estados Unidos desde 1917, o qual evidenciava claramente um modelo de formação de enfermeiros voltado para a área hospitalar. A autora ressalta ainda, que embora a Escola Ana Neri tivesse seu programa de ensino regulamentado pelo governo brasileiro em 1923, a sua grade de disciplinas apresentava praticamente a mesma estrutura da grade curricular americana.

Ao analisar o currículo da primeira Escola de Enfermagem brasileira, Gomes (1991) destaca a presença de duas disciplinas de administração, Administração Hospitalar e Serviço Administrativo Hospitalar, e ressalta que o conheci- mento administrativo na enfermagem se constituiu tanto na Inglaterra e Estados Unidos quanto no Brasil, considerando-se, logicamente, que tal conhecimento foi introduzido na enfermagem de cada um desses três países em resposta a um conjunto de determinantes históricos-sociais específicos para cada um deles (Gomes, 1991).

Historicamente as enfermeiras têm adotado princípios da Escola Científica e Clássica da Administração para gerenciarem o seu trabalho, tendo em vista a estrutura e organização do Serviço de Enfermagem nas instituições de saúde (Fernandes et al., 2003). Os princípios deste modelo de gerência foram preconizados por Taylor e Fayol, em meados do século 19 e utilizados inicialmente na organização do trabalho realizado nas indústrias. Contudo, a administração hospitalar e conseqüentemente a administração em enfermagem mais tarde também foram influenciadas por este estilo de gerência (Spagnol, 2002).

Parte-se do princípio que o enfermeiro ainda utiliza métodos e estratégias de gestão tradicionais, oriundos da teoria clássica da administração, modelo que foi determinado historicamente por fatores econômicos, sociais e culturais.

Para Ferraz (1995), a lógica do controle é uma característica marcante deste modelo de gerência que influenciou a enfermagem, desde a sua institucionalização. Ressalta ainda, que esta forma racionalizada de se organizar o trabalho, determina aos trabalhadores a maneira de se executar as tarefas, centralizando as ações do gerente na supervisão (controle, grifo da autora deste trabalho) da sua equipe. Nesta perspectiva, para gerenciar a assistência de enfermagem, o enfermeiro utiliza a supervisão como dispositivo de controle do processo de trabalho e do comportamento dos trabalhadores, dificultando o exercício da gerência compartilhada.

Portanto, este estilo de gerência tradicional não tem permitido aos trabalhadores da enfermagem criarem espaços coletivos de gestão, onde possam atuar como atores sociais, ou seja, compartilharem o processo decisório e adquirirem capacidade coletiva de análise para resolverem seus problemas e identificarem suas demandas.

De acordo com Spagnol (2000) apesar das contribuições do modelo clássico de gerência à organização do trabalho na área hospitalar, ao longo do tempo, este tem produzido efeitos negativos que prejudicam o processo de trabalho. Dentre eles, cita as dificuldades para responder 
prontamente às necessidades dos clientes e dos trabalhadores, interferindo de forma significativa na qualidade dos serviços prestados, pois o trabalho da enfermagem é desenvolvido, mecanicamente, sem maiores vínculos com os clientes e com os problemas do cotidiano.

Este estilo de gerência adotado pela enfermagem foi descrito e criticado por vários autores como: Santos (1986); Trevizan et al. (1991); Carrasco (1993); Collet et al. (1994); Ferraz (1995); Fávero (1996); Bellato et al. (1997); Lima, M.A.D.S. (1998); Lima, R.C.D. (1998); Spagnol (2002), entre outros, que defendem e apostam numa outra configuração para a gerência em enfermagem nos serviços de saúde.

Corroborando com estes autores e pensando na formação dos futuros enfermeiros, bem como na qualificação das práticas da enfermagem, pergunta-se: como buscar uma outra configuração para a gerência em enfermagem que não esteja pautada nos princípios da Teoria Clássica da Administração? Como delinear uma outra prática gerencial para o enfermeiro que seja alternativa a este modelo tradicional de gestão e ao mesmo tempo esteja comprometida com a vida dos clientes e dos trabalhadores?

Estas questões são significativas e têm trazido alguns incômodos a determinados profissionais e intelectuais da saúde, os quais têm constantemente questionado a pertinência e adequação deste modelo tradicional de gerência na sociedade contemporânea, uma vez que este foi criado para atender as demandas das indústrias, em meados do século 19, sendo posteriormente adotado e adaptado para o setor saúde.

Sendo assim, para se configurar outras propostas para a gerência em enfermagem, que estejam pautadas em princípios éticos, democráticos e que focalizem no processo de trabalho, o trabalhador e o cliente dos serviços de saúde como atores sociais que têm interesses, desejos e necessidades, faz-se necessário buscar outros referenciais teóricos, que vão além das teorias administrativas para subsidiar uma nova prática gerencial. No exercício da gerência, o enfermeiro precisa deixar de supervalorizar somente o controle, a hierarquia, a ordem e a impessoalidade, para instituir práticas como a análise do processo de trabalho, o diálogo, a participação e o debate junto com sua equipe e com a equipe multiprofissional.

Assim, para subsidiar algumas reflexões acerca da gerência em enfermagem pode-se encontrar aporte teórico nas obras relacionadas à temática da gestão em saúde, elaboradas prin- cipalmente pelos autores Merhy \& Onocko (1997), Cecílio (1997) e Campos (2000 b), todos sanitaristas vinculados ao Departamento de Medicina Preventiva da Faculdade de Ciências Médicas da Universidade Estadual de Campinas, que atuam nas diversas áreas da Saúde Coletiva. Além disso, para compreender melhor o objeto dos meus estudos - a gerência em saúde e especificamente na enfermagem, busquei me inserir no curso de doutorado em Saúde Coletiva oferecido pela referida instituição, que possui linhas de pesquisa, nas quais alguns pesquisadores buscam desenvolver seus estudos, na perspectiva de compreender o trabalho e os processos de gestão em saúde, tendo em vista a defesa do sistema público de saúde e formas democráticas de gestão deste sistema.

A Saúde Coletiva tem se constituído em um importante campo de conhecimento que utiliza conceitos e categorias de diversas disciplinas (epidemiologia, biologia, administração, sociologia, antropologia, filosofia, economia, entre outras) para compreender os determinantes sociais do processo saúde-doença, elaborar e analisar as políticas de saúde, bem como compreender as práticas de gestão dos serviços. Por exemplo, conceitos e categorias como: coletivo, sujeito, ator social, subjetividade, autogoverno, responsabilização, planejamento estratégico, trabalho vivo, trabalho morto, vínculo, acolhimento, autonomia, estrutura social, entre outros, são encontrados na produção científica da Saúde Coletiva, tanto nas análises de caráter macrossocial, quanto nas análises de intervenções em processos microssociais que ocorrem nos serviços de saúde.

Parte-se do pressuposto que alguns destes conceitos poderão subsidiar a configuração de uma nova prática gerencial na enfermagem, pois entende-se a gerência como uma prática coletiva, ou seja, relacional, que deve compreender o cliente e o trabalhador de saúde como um sujeito social em ação.

Neste sentido, partindo do princípio que a gerência em enfermagem necessita, na atualidade, ser vista e exercitada sob um novo olhar, procurei aqui elaborar uma reflexão acerca desta prática gerencial, utilizando os conceitos de sujeito social e de coletivo, que são fundamentais no campo da Saúde Coletiva. A reflexão poderá apontar novas perspectivas de atuação do enfermeiro, na qualidade de gerente da assistência, no seu fazer cotidiano. 


\section{Saúde Coletiva: identificando este campo de conhecimento}

O conceito de campo científico elaborado por Bourdieu (1994) pode ser um dos pontos de partida para uma aproximação e compreensão do campo da Saúde Coletiva, visto que este apresenta várias dificuldades, iniciando-se principalmente pela sua própria definição.

Para Bourdieu (1994) o campo científico, enquanto sistema de relações objetivas entre posições adquiridas (em lutas anteriores), é o lugar, o espaço de jogo de uma luta concorrencial, sendo que o monopólio da autoridade científica é o que está em jogo neste campo. Esta autoridade científica ou competência científica pode ser definida como capacidade técnica e poder social, entendida como capacidade de falar e agir legitimamente (isto é, de maneira autorizada e com autoridade), que é socialmente outorgada a um agente determinado.

Diante do conceito apresentado, penso que o campo da Saúde Coletiva pode ser visto como uma arena em que vários conceitos, referenciais teóricos e metodológicos estão sendo disputados entre os diversos atores que marcam suas posições políticas e ideológicas, evidenciando a pluralidade e as imprecisões que caracterizam este campo.

$\mathrm{Na}$ sociedade contemporânea, grande parte dos campos científicos ou de práticas tem caráter multiprofissional e apresenta como característica marcante a interdisciplinaridade, tornando-se inevitável a ocorrência de limites indeterminados e uma certa sobreposição entre as diversas disciplinas que constituem as áreas do conhecimento (Campos, 2000a). Nesta perspectiva, foi se constituindo então, ao longo da história, o campo da Saúde Coletiva, sendo considerado de natureza interdisciplinar, pois congrega diversas disciplinas que se interpõem.

De acordo com Nunes (2002) a dificuldade para se definir o campo da Saúde Coletiva encontra-se principalmente no fato de ser uma criação que transborda os limites disciplinares e que se apresenta na interface de áreas do conhecimento detentoras de especificidades teóricas e conceituais, procedentes das ciências biológicas, sociais, matemáticas e epidemiológicas, que foram elaboradas ao longo de quase dois séculos (Nunes, 2002).

Nesta direção, Paim \& Almeida Filho (1998) referem que a Saúde Coletiva não é uma disciplina científica, uma ciência ou mesmo uma especialidade médica, mas sim um campo de co- nhecimento plural, composto por disciplinas básicas tais como: a epidemiologia, as ciências sociais em saúde, o planejamento e a administração em saúde. Além disso, pondera que a demografia, a geografia, a clínica, a genética, a estatística, as ciências biomédicas, entre outras, também são disciplinas que compõem este campo, porém são de caráter complementar.

Luz (1997) refere que a psicanálise, a psicologia, a história, a política, a economia, a sociologia, a antropologia e a filosofia, todas vinculadas às ciências humanas e sociais, são disciplinas que também contribuem para a composição do campo da Saúde Coletiva. Ressalta que todas as disciplinas que se agregam a este campo estão sempre discutindo a problemática da saúde em uma perspectiva social, isto é, do coletivo.

Sendo assim, a Saúde Coletiva abrange um conjunto complexo de saberes e práticas relacionados ao campo da saúde, envolvendo desde organizações que prestam assistência à saúde da população até instituições de ensino e pesquisa e organizações da sociedade civil (L'Abbate, 2003).

Saúde Coletiva é um termo utilizado exclusivamente no Brasil, que surgiu no fim da década de 1970 em virtude principalmente do movimento de um grupo de profissionais que acreditava no processo de democratização do País em oposição ao regime militar. Dentre outras, as inquietações destes profissionais estavam voltadas para o reordenamento das práticas de saúde vigentes naquela época e para a formação de profissionais, essencialmente nos níveis de pós-graduação stricto sensu e lato sensu. Além disso, estavam preocupados também com a produção de conhecimentos e a formulação de novas políticas para a área da saúde que atendessem de fato as necessidades da população (Canesqui, 1995).

Assim, falar de Saúde Coletiva no Brasil éfalar de um campo de conhecimento, de uma prática sociopolítica, de uma visão filosófica, ou se$j a$, de uma atividade que se conforma numa dimensão teórica, num movimento e num pensamento (Nunes, 2002).

O referido autor sintetiza que a Saúde Coletiva pode ser caracterizada como um movimento contra-hegemônico que possuí uma dimensão sociopolítica e que nasceu nos anos 70 , principalmente, em virtude da crise e dos questionamentos acerca do sistema de saúde vigente, da necessidade de se institucionalizar a pesquisa e a formação de profissionais da saúde, as quais estavam dispersas em várias instituições, 
bem como da importância de se elaborar políticas e se realizar práticas, visando à melhoria das condições de saúde da população. Além disso, este movimento da Saúde Coletiva contribuiu efetivamente para a construção do Sistema Único de Saúde (SUS) no Brasil, que foi descrito e legalizado na Constituição de 1988.

Segundo Nunes (2002), a Saúde Coletiva herdou conceitos e categorias de diversos campos de saberes, notadamente da biologia, sociologia, antropologia, história, epidemiologia, psicanálise, ciências políticas e administrativas (...), além de tentar definir as especificidades de seu próprio campo. Assim, neste ensaio teórico, pretende-se utilizar os conceitos de sujeito social e de coletivo, que fazem parte deste campo do conhecimento, buscando articulá-los à gerência em enfermagem, uma vez que são significativos para (re)pensar o estilo de gerência, racional e hegemônico, adotado pelos enfermeiros, principalmente na área hospitalar.

\section{Coletivo e sujeito social: conceitos que podem contribuir para uma reflexão acerca da prática gerencial da enfermagem}

Neste ensaio, com o objetivo de elaborar uma reflexão acerca da gerência em enfermagem, procurou-se trazer a visão de alguns autores que abordam a questão do sujeito social e do coletivo, como um dos pontos fundamentais para se pensar os processos de gestão em saúde na sociedade contemporânea. Portanto, a partir destas abordagens conceituais, pretende-se fazer um paralelo com a prática gerencial exercida especificamente pelo enfermeiro, que tem sob sua responsabilidade a coordenação da assistência e da equipe de enfermagem, não esquecendo que esta atividade está inserida no processo de trabalho em saúde.

Torna-se fundamental, para discutir a prática gerencial da enfermagem, tendo em vista a visão de homem, como sujeito social, considerar a formulação de Matumoto et al. (2001), que incita a pensar uma outra concepção de homem. Uma concepção que o reconheça como um ser social em constante interação com os outros homens e com seu meio, transformando-o e sendo transformado por ele. Ainda nesta direção, inclui-se a concepção de Testa, que defende a idéia de se compreender o homem como um ser constituído socialmente, ou seja, um ator social que tem um projeto, uma intencionalidade no seu fazer, e que está constantemente produzindo fatos sociais (Testa apud Matumoto et al., 2001).

Nesta perspectiva, L'Abbate (1995) refere que, atualmente, parte da literatura produzida especificamente no campo da Saúde Coletiva tem discutido a necessidade de uma mudança conceitual no termo Recursos Humanos em Saúde, buscando substituí-lo por profissionais em saúde, ou por sujeitos, tendo em vista que estes últimos são capazes de atuar para serem não apenas reprodutores das práticas de saúde, mas produtores de novas práticas.

Segundo L'Abbate (1994), sujeito seria uma pessoa em busca de autonomia, disposta a correr riscos, a abrir-se ao novo, ao desconhecido, e na perspectiva de ser alguém que vive numa sociedade determinada, capaz de perceber seu papel pessoal/profissional/social diante dos desafios colocados a cada momento.

Campos (2000b) também conceitua sujeito social, dizendo que este é um ser biológico que possui uma subjetividade complexa. $\mathrm{O}$ autor explica ainda que o sujeito é um ser imerso na história e na sociedade, mas nem por isso despossuído de uma subjetividade singular e de capacidade para reagir ao seu contexto. Está constantemente produzindo relações sociais que modificam seus projetos, mas também possui autonomia relativa para realizar os seus desejos, buscar os seus interesses e satisfazer as suas necessidades.

Compreender o trabalhador de saúde levando em conta definições como as dos autores acima, segundo Minayo (2001), não tem sido a tônica dos processos de gestão desenvolvidos nas organizações de saúde, uma vez que os seus dirigentes, na maioria das vezes, utilizam métodos gerenciais que destacam as relações técnicas (normas, funções e papéis) em detrimento a outros que valorizam a lógica das relações sociais, como aspecto essencial no exercício da gerência.

Neste contexto, Campos (1997b) destaca que dificilmente a administração e o planejamento têm contemplado a produção de sujeitos sociais, como um dos seus objetivos principais, pois existe uma tradição nas organizações, dentre elas as de saúde, em se controlar os trabalhadores, ao invés de estimulá-los a se constituírem como sujeitos sociais, autônomos e responsáveis.

Sendo assim, tomando como ponto de apoio esta discussão realizada no campo da Saúde Coletiva, propõe-se que a partir de ago- 
ra, na prática gerencial, os recursos humanos em enfermagem (enfermeiros, técnicos e auxiliares) sejam compreendidos, como sujeitos sociais em ação, visto que não são objetos, mas sim, seres humanos dotados de interesses próprios, de necessidades e de desejos, que produzem relações sociais, na medida em que interagem constantemente com outros sujeitos e podem adquirir capacidade para intervir na sua realidade. Portanto, trata-se de apreender esta noção de sujeito, como um dos pressupostos fundamentais que poderá servir de guia norteador para (re) direcionar o processo de gerência na profissão.

Corroborando com os autores citados e partindo do princípio que na prática gerencial os trabalhadores da enfermagem devem ser compreendidos como sujeitos sociais, outro ponto relevante para esta reflexão é buscar uma outra visão de gerência (neste ensaio optou-se por não diferenciar os termos gerência e gestão, assim, serão entendidos com o mesmo significado) que não esteja pautada nos princípios e conceitos que subsidiam o modelo clássico de gestão.

Segundo Mishima et al. (2000), a atividade gerencial é uma ação intencional voltada para a consecução de objetivos, a qual detém caráter articulador e integrativo, sendo determinada e determinante no processo de organização dos serviços de saúde e fundamental para a efetivação de politicas sociais, em específico as da saúde.

Tendo em vista seu caráter articulador e integrativo, Campos (2000b) defende a proposta de co-gestão, ou seja, para ele a gestão dos serviços de saúde deve ser uma atividade coletiva e não somente uma atividade atribuída a poucos profissionais ou especialistas que detêm e centralizam o poder.

Mas afinal, o que significa a palavra coletivo no contexto da saúde? Para Donnangelo (1983) a palavra coletivo apresenta diversas conotações e significados como: coletivo/meio; coletivo/conjunto de indivíduos; coletivo interação entre elementos; coletivo como conjunto de efeitos ou conseqüências da vida social; coletivo transformado em social como campo específico e estruturado de práticas. Este é um termo impreciso que vem das Ciências Sociais e foi adotado na Saúde Coletiva, devido aos seus múltiplos significados, o que segundo a autora citada, torna-se adequado para caracterizar a diversidade de aspectos existente no campo da saúde e principalmente no campo da Saúde Coletiva (L'Abbate, 2003).

Ao fazer uma aproximação ao conceito de coletivo, como campo estruturado de práticas sociais, buscou-se como referência Campos (2000b), que discute a conformação de espaços coletivos, como um lugar de reflexão crítica, produção de subjetividade e constituição de sujeitos.

Para Campos (2000b) espaços coletivos são espaços concretos (de lugar e tempo) destinados à comunicação (escuta e circulação de informações sobre desejos, interesses e aspectos da realidade), à elaboração (análise da escuta e das informações) e à tomada de decisão (prioridades, projetos e contratos).

De acordo com o autor estes espaços coletivos são arranjos que podem tomar a forma de equipes de trabalho, conselhos de co-gestão, assembléias, colegiados de gestão, reuniões, unidades de produção, entre outros (Campos, 2000b). Estes espaços constituem-se em locais concretos de produção de subjetividade e busca de autonomia dos trabalhadores. Sendo assim, o coletivo organizado para produção transcende cada um dos sujeitos que o constitui, formando uma rede de relações tecida entre os sujeitos que o compõem e o contexto em que estão inseridos (Campos, 2000b).

Entendendo a gerência como uma prática social, convidam-se os enfermeiros, os técnicos e os auxiliares para, juntos, pensarmos a gerência em enfermagem, como uma prática que, necessariamente, precisa construir espaços coletivos, onde os diversos profissionais, envolvidos direta ou indiretamente, possam analisar constantemente o seu processo de trabalho, além de poder compartilhar suas decisões e ações realizadas.

Portanto, torna-se essencial compreender a equipe de enfermagem como um coletivo de sujeitos sociais, que estabelecem uma teia de relações, tecida cotidianamente pelos seus profissionais (enfermeiros, técnicos e auxiliares de enfermagem), somando-se a isto as relações constituídas também pelos diversos profissionais de saúde. Este coletivo organizado possui como objetivo principal a prestação de uma assistência integral à população, que necessita dos serviços de saúde. Por outro lado, estes serviços precisam estar estruturados para atingir a sua finalidade produtiva, ou seja, a produção de ações de saúde, realizadas de forma ética, digna e segura.

\section{Considerações finais}

Apesar da mudança de paradigma proposta pelas teorias contemporâneas da administração, as quais estão pautadas na organização do tra- 
balho em equipe, redução das linhas hierárquicas e intensa comunicação horizontal, observase que, na maioria das organizações, a enfermagem ainda reproduz nas suas relações a herança do estilo tradicional de gerência. Assim, as relações hierárquicas são rígidas e o poder decisório ainda está centrado na figura do enfermeiro "chefe" que dá as ordens aos seus "subordinados". Este por sua vez, parece que, na maioria das vezes, também mantém no imaginário a figura do enfermeiro que se graduou somente para mandar e dar ordens de forma autoritária.

No cotidiano de trabalho estas relações rigidamente hierarquizadas são, às vezes, reais quando determinados enfermeiros adotam uma postura autoritária perante a equipe, mas em alguns momentos não passam de imagens e estereótipos da figura deste profissional, que foram historicamente construídos ao longo do tempo e que atualmente necessitam ser (des)construídos para se construir novas relações de trabalho na saúde e na enfermagem.

O contexto atual mostra a necessidade de se criar espaços coletivos e democráticos nas organizações que permitam aos gerentes e trabalhadores analisar suas relações de trabalho, explicitando e conduzindo os conflitos, tendo em vista a produção de sujeitos em espaços coletivos organizados. Assim, o enfermeiro necessita compreender as relações e as demandas do seu grupo de trabalho para juntos elaborarem, de forma compartilhada, projetos terapêuticos que atendam às necessidades da população que procuram os serviços de saúde.

O enfermeiro, como coordenador da equipe de enfermagem, é um profissional que necessita ter subsídios teóricos e vivências práticas para gerenciar a assistência juntamente com sua equipe. Como gerente da assistência, este profissional deve ser capaz de identificar, analisar e conduzir as relações de trabalho sem que estas interfiram de forma negativa na assistência prestada aos clientes.

Sendo assim, a função gerencial desempenhada pelo enfermeiro nos serviços de saúde deve contemplar os aspectos assistencial, pedagógico, técnico-científico e político, bem como aqueles que dizem respeito às relações interpessoais, visando ao planejamento de uma assistência integral, prestada de forma segura e livre de riscos, ao indivíduo, à família e à comunidade.
Como docente responsável pela formação dos futuros enfermeiros, penso que estes profissionais têm um papel fundamental na produção de sujeitos sociais, em que os trabalhadores (incluindo-se neste processo) possam analisar e refletir coletivamente o seu processo de trabalho, tendo em vista a prestação de uma assistência de enfermagem de forma ética, digna e humanizada.

Nesta perspectiva, é preciso encontrar estratégias de intervenção que propiciem aos trabalhadores deixarem de ser subordinados e passivos, os quais somente acatam as ordens dos seus superiores e deixam de exercer o seu papel de sujeitos produtivos e criativos no desenvolvimento do trabalho. Além disso, a formação destes profissionais, gerentes, deve possibilitar a aquisição de um referencial teórico, de análise e de intervenção, que permita uma reflexão constante da sua prática gerencial, do seu papel como coordenador da equipe de enfermagem e das relações sociais inerentes ao ambiente de trabalho.

Assim, aproximar do campo da Saúde Coletiva, tomando os conceitos de sujeito social e de coletivo utilizados neste campo, para elaborar esta reflexão acerca da prática gerencial do enfermeiro, contribuiu para ampliar meus conhecimentos e questionamentos a respeito da gerência no setor saúde, mais especificamente a gerência em enfermagem.

Neste sentido, a Saúde Coletiva é um dos campos de conhecimento que pode contribuir para a (re)construção do exercício da gerência na enfermagem, pois parte da sua produção científica congrega conceitos e categorias analíticas que permitem pensar e intervir na problemática da gerência em saúde, contribuindo para se (re)pensar a prática gerencial da enfermagem.

Por fim, um aspecto relevante para esta reflexão é a visão que Campos (1997a) tem da gestão em saúde. Este autor propõe, a partir de novos conhecimentos e novas formas de agir, superar o eixo central de todas as escolas de administração que buscam de diferentes maneiras reduzir sujeitos humanos à condição de instrumentos dóceis aos objetivos da empresa, transformando-os em insumos ou em objetos. Neste sentido, enfatiza que o desafio atual dos dirigentes está pautado na diretriz de se "governar para produzir sujeitos !" 


\section{Referências bibliográficas}

Backes VMS 1999. O legado histórico do modelo nightingale: seu estilo de pensamento e sua práxis. Revista Brasileira de Enfermagem 52(2):251-264

Bellato R et al. 1997. Algumas reflexões sobre o método funcional no trabalho da enfermagem. Revista Latino Americana de Enfermagem 5(1):75-81.

Bourdieu P 1994. O campo científico, pp. 122-155. In R Ortiz (org.). Pierre Bourdieu: sociologia. Ed. Ática, São Paulo.

Campos GWS 1997a. Considerações sobre a arte e a ciência da mudança: revolução da coisas e reforma das pessoas - o caso da saúde, pp. 29-87. In LCO Cecílio (org.). Inventando a mudança na saúde. Hucitec, São Paulo.

Campos GWS 1997b. Subjetividade e administração de pessoal: considerações sobre modos de gerenciar o trabalho em equipes de saúde, pp. 229-266. In EE Merhy \& R Onocko (orgs.). Agir em saúde- um desafio para o público. Ed. Hucitec, São Paulo.

Campos GWS 2000a. Saúde Pública e Saúde Coletiva: campo e núcleo de saberes e práticas. Ciência e Saúde Coletiva 5(2):219-230.

Campos GWS 2000b. Um método para análise e co-gestão de coletivos: a constituição do sujeito, a produção de valor de uso e a democracia em instituições - o método da roda. Hucitec, São Paulo.

Canesqui AM 1995. Ciências sociais, a saúde e a Saúde Coletiva, pp. 19-35. In AM Canesqui (org.). Dilemas e desafios das Ciências Sociais na Saúde Coletiva. Hucitec, São Paulo.

Carrasco MAP 1993. Influência das escolas de administração científica e clássica na produção científica da enfermagem brasileira. Revista da Escola de Enfermagem USP 27(01):43-65.

Cecílio LCO (org.) 1997. Inventando a mudança na saúde. Hucitec, São Paulo.

Collet N et al. 1994. Método funcional na administração em enfermagem: relato de experiência. Revista Brasileira de Enfermagem 45(2/3):187-199.

Donnangelo MCF 1983. A pesquisa na área da Saúde Coletiva no Brasil - a década de 70. Abrasco: Ensino da Saúde Pública, Medicina Preventiva e Social no Brasil 02:19-35.

Fávero N 1996. O gerenciamento do enfermeiro na assistência ao paciente hospitalizado. Tese de livre docência. Escola de Enfermagem de Ribeirão Preto, Universidade de São Paulo, Ribeirão Preto, 92 pp.

Fernandes MS, Spagnol C, Trevizan MA \& Hayashida M 2003. A conduta gerencial da enfermeira: um estudo fundamentado nas teorias gerais da administração. Revista Latino-Americana de Enfermagem 11(2):161-167.

Ferraz CA 1995. A transfiguração da administração em enfermagem: da gerência científica à gerência sensivel. Tese de doutorado. Escola de Enfermagem de Ribeirão Preto, Universidade de São Paulo, Ribeirão Preto, 248 pp.

Gomes ELR 1991. Administração em enfermagem: constituição histórico-social do conhecimento. Tese de doutorado. Escola de Enfermagem de Ribeirão Preto, Universidade de São Paulo, Ribeirão Preto, 188 pp.

L'Abbate S 1995. Agentes de trabalho/sujeitos? Repensando a capacitação de recursos humanos em Saúde Coletiva, pp. 151-161. In AM Canesqui (org.). Dilemas e desafios das ciências sociais na Saúde Coletiva. Hucitec, São Paulo.
L'Abbate S 2003. A análise institucional e a Saúde Coletiva. Ciência e Saúde Coletiva 8(1):265-274.

L’Abbate S 1994. Educação em saúde: uma nova abordagem. Cadernos de Saúde Pública 10(4):481-490.

Lima MADS 1998. O trabalho de enfermagem na produção de cuidados de saúde no modelo clínico. Tese de doutorado. Escola de Enfermagem de Ribeirão Preto, Universidade de São Paulo, Ribeirão Preto, 216 pp.

Lima RCD 1998. A enfermeira: uma protagonista que produz o cuidado no cotidiano do trabalho em saúde. Tese de doutorado. Faculdade de Ciências Médicas, Universidade de Campinas, Campinas, 243pp.

Luz MT 1997. A produção científica em Saúde Coletiva: 1994-1995. Ciência e Saúde Coletiva 2(1/2):117-141.

Matumoto S, Mishima S \& Pinto IC 2001. Saúde Coletiva: um desafio para a enfermagem. Cadernos de Saúde Pública 17(1):233-241.

Merhy EE \& Onocko R (orgs.) 1997. Agir em saúde - um desafio para o público. Hucitec, São Paulo.

Minayo MCS 2001. Estrutura e sujeito, determinismo e protagonismo histórico: uma reflexão sobre a práxis da Saúde Coletiva. Ciência e Saúde Coletiva 6(1):7-19.

Mishima S, Villa TCS, Silva E, Pinto IC \& Almeida MCP 2000. O velho trabalho em equipe pode ganhar cara nova? Uma perspectiva do trabalho gerencial. Saúde em Debate 24(54):66-74.

Nightingale F 1989. Notas sobre a enfermagem: o que é e o que não é. Cortez, São Paulo.

Nunes ED 2002. As bases históricas e epistemológicas da Saúde Coletiva, pp. 45. Seminário Regional "Tendências e perspectivas da investigação e da formação em Saúde Coletiva", Rio Grande do Sul.

Paim JS \& Almeida Filho N 1998. Saúde Coletiva: uma "nova saúde pública" ou campo aberto a novos paradigmas? Revista Saúde Pública 32(4):299-316.

Pires D 1989. Hegemonia médica na saúde e a enfermagem: Brasil de 1500 a 1930. Ed. Cortez, São Paulo.

Rizzotto MLF 1995. (Re)vendo a questão da origem da enfermagem profissional no Brasil: a Escola de Anna Nery e o mito da vinculação com a Saúde Pública. Trajetos 2(5):110-123.

Santos I 1986. Teorias organizacionais em administração em enfermagem: pontos para reflexão. Revista Baiana Enfermagem 2(2):74-93.

Spagnol C 2002. Da gerência clássica à gerência contemporânea: compreendendo novos conceitos para subsidiar a prática administrativa da enfermagem. $R e-$ vista Gaúcha de Enfermagem 23(1):114-131.

Spagnol C 2000. Tendências e perspectivas da administração em enfermagem: um estudo na Santa Casa de Belo Horizonte-MG. Tese de mestrado. Escola de Enfermagem de Ribeirão Preto, Universidade de São Paulo, Ribeirão Preto, 177 pp.

Trevizan MA et al. 1991. Utilização das teorias administrativas na produção do conhecimento sobre administração em enfermagem. Revista Brasileira de Enfermagem 44(4):36-40.

Artigo apresentado em 25/12/2003

Aprovado em 15/10/2004

Versão final apresentada em 19/10/2004 